\title{
Flying in Different Directions
}

ONE aspect of North American life which Europeans would most willingly import is the low cost of air travel. Costs of travelling about Europe by air remain obstinately high, and show scarcely any signs of falling. At the same time, airline profitability is low, and the system seems unable to generate sufficient traffic to enable fares to fall. The situation in cargo transport is no better than in passenger aircraft-indeed, it may be worse. These problems were put with depressing clarity when M. Pierre Cot, director-general of Air France, addressed a recent meeting of IATA in Munich.

The problem, M. Cot explained, is caused by Europe's diversity, and the consequent proliferation of airlines too small to be really efficient. The problem of settling routes within Europe was itself difficult enough to ensure that European airlines would always be topheavy, with twice the management costs of the American carriers. This means that, although wage levels in the United States are much higher, the staff costs per tonne-kilometre are 40 per cent less. Equally, political differences make it impossible for European carriers to achieve the optimum utilization of their aircraft, a difficulty made the more acute by relatively low traffic densities. M. Cot pointed out that the busiest American route, between Los Angeles and San Francisco, carries $3 \cdot 3$ million passengers a year, and there are sixty-five flights a day in each direction; in Europe, the densest route is between London and Paris, with $1 \cdot 25$ million passengers a year, and twentyeight flights a day in each direction. Similarly, the London to Amsterdam run carries only 0.5 million passengers a year, while the New York to Boston run generates $2 \cdot 25$ million. These traffic densities are shown by the revenue carned by the airlines; neglect- ing the four largest American carriers, M. Cot said that the average American airline had a revenue three times as great as the average European carrier.

All this, it could be argued, is merely evidence of a transient phase through which the airlines in Europe are passing on their way to becoming large and profitable. M. Cot sees no such comfortable solution, and he spoke in Munich of the renewed efforts being made by the railways to recapture traffic, principally from the roads but also from the airlines. With capital expenditure behind them, railways start with a distinct advantage, and there is plenty of evidence of ways in which railway systems can be quite dramatically increased in capacity and passenger appeal by increasing speeds. British Rail plans to do this for $£ 10$ million, by putting its advanced passenger train into service, and $£ 10$ million is scarcely more than it will cost to buy a single American SST. As M. Cot put it, "The price of a single American SST will be equal to that of a large steel rolling mill".

What this means is that the airline industry is fast becoming a major consumer of capital, in the same league as the oil industry, electricity generation, or the iron and steel industry. Once this is realized, it can readily be seen that in Europe there arc far too many airlines looking for too little cash. M. Cot suggested some palliative measures-more efficient management, more extensive use of existing facilities before expensive new ones are built, and the like - but the real solution is likely to be a sweeping rationalization of the whole airline business. The most logical-and least likelysolution would be the formation of a single European airline, but while national pride is bound up in national airlines this is unlikely to come about.

\section{Engineers a Cubit Higher}

THE Hippocratic oath of the medical profession has cxcited the attention of several moralists, not all of whom have paid equal regard to the reasons for which doctors in Britain, at lcast, no longer take it, sign it or swear by it. Mr K. W. Matthews, a civil servant with the United Kingdom Atomic Energy Authority, has recently called for an equivalent oath for engineers, which, he believes, would act as a "permanent inspira. tion and make their place in the community challengingly clear". (The Chartered Mechanical Engineer, November 1968.) But why should engineers need a code of ethics? And why are the Ten Commandments not enough? One possibility which has often been suggested is that war could be abolished if those who make its instruments were to forswear aggression. Brecht's Galileo, for example, says that unless scientists can devise something like the Hippocratic oath of the doctors, "the best that can be hoped for is a race of inventive dwarfs who can be hired for anything".

Whatever the merit of this proposal, which recent discussions about biological warfare on both sides of the Atlantic have shown to be at least fertile ground for argument, it is not here that $\mathrm{Mr}$ Matthews has chosen to sow his dragon's teeth. Indeed, the absence of any reference to war is one of the curiosities of his proposed code of ethics. On his view, the code is necessary because modern approaches to management, such as cost-effectiveness, conflict with the traditional engineering ideal of building the best and the most lasting. At a time of changing values, engineers should form a rock of steadfastness by adopting a code of ethics which, it is implied, would gain them a professional prestige similar to that enjoyed by doctors and lawyers.

Unfortunately, it is not so clear that engineers could add a cubit to their moral stature in this way, unless it can be shown that such a code is both necessary and 